\title{
Uma encruzilhada do Ocidente: o Caribe setecentista como espaço histórico
}

\author{
A crossroads of the West: the 18th-Century Caribbean as a historic space \\ Una encrucijada del Occidente: el Caribe del siglo XVIII como espacio histórico
}

\author{
Jaime Rodrigues ${ }^{1 *}$ \\ ${ }^{1}$ Universidade Federal de São Paulo, Guarulhos/SP - Brasil
}

Scotт, Julius S. The Common Wind: Afro-American Currents in the Age of the Haitian Revolution. Londres; Nova York: Verso, 2018. 246 p.

Professor emérito do Departamento de Estudos Afro-Americanos e Africanos da University of Michigan, nos Estados Unidos, Julius Sherrard Scott III doutorou-se em 1986 na Duke University, em Ann Arbor, com a tese intitulada The Common Wind: Currents of Afro-American Communication in the Era of the Haitian Revolution. Com uma ligeira mudança no subtítulo, a tese ganhou o formato de livro em 2018: The Common Wind: Afro-American Currents in the Age of the Haitian Revolution. Os mesmos cinco capítulos da tese compóem o livro, acrescido de um prefácio escrito por
Marcus Rediker, ${ }^{1}$ professor da University of Pittsburgh, já bem conhecido do leitor brasileiro, com quem o diálogo e a perspectiva teórica da história vista de baixo são evidentes.

É difícil entender o intervalo de mais de trinta anos entre a defesa da tese e a impressão do livro, sobretudo porque o conteúdo manteve-se praticamente inalterado, porque o assunto é relevante e a narrativa é bem construída. Desinteresse editorial, desejo do autor em rever sua obra ou espera por um momento oportuno para reavivar a lembrança coletiva de que o Haiti ainda existe, como o terremoto de 2010, talvez possam ser elencados como hipóteses possíveis para essa longa espera. A bibliografia sobre o Haiti e, de forma mais ampla, o Grande Caribe, como Scott aborda no livro, não é extensa

${ }^{1}$ Autor de $A$ hidra de muitas cabeças: marinheiros, plebeus e a história oculta do Atlântico revolucionário (em parceria com Peter Linebaugh) (2008) e O navio negreiro: uma história humana (2011).

DOI: http://dx.doi.org/10.1590/2237-101X02204613

Resenha recebida em 2 de fevereiro de 2020 e aceita para publicação em 7 de abril de 2020.

* Professor da Universidade Federal de São Paulo / Escola de Filosofia, Letras e Ciências Humanas / Departamento de História, Guarulhos/SP - Brasil. E-mail: rodriguesjaime@gmail.com. ORCID: https://orcid. org/0000-0002-9893-7365. 
em inglês e é praticamente inexistente em português. ${ }^{2}$ Por isso, talvez o primeiro ponto a ser destacado nesta resenha seja a necessária iniciativa de traduzir esse livro no Brasil, sem esperar a passagem de outras três décadas para que os leitores possam acessar uma experiência tão próxima à história colonial e imperial do país e tâo inspiradora para os estudos históricos sobre a formação cultural brasileira e a história marítima ainda pouco praticada por aqui.

Chama a atenção a profusão e diversidade de materiais de que Scott se valeu para a escrita de sua história da circulação de ideias revolucionárias no Caribe setecentista: manuscritos oficiais de agentes da Coroa em arquivos espanhóis e cubanos, o mesmo tipo de fontes para a administração britânica em Londres e nas Índias Ocidentais, documentos de fundos privados em coleçóes estadunidenses, baladas cantadas por marinheiros negros e brancos em circulação por aquelas águas, narrativas de viajantes, propaganda abolicionista e jornais editados na América do Norte, nas Antilhas, no Reino Unido e na França. Exceto por periódicos que circularam em Port-au-Prince e Cap Français, as fontes haitianas são praticamente ausentes do estudo, sinal de seu desaparecimento ou inacessibilidade ao longo da conturbada história humana e natural do país desde o século XVIII.

"Pandora's Box: The Masterless Caribbean at The End of the 18th Century", o capítulo inicial, anuncia o contexto da ação

\footnotetext{
${ }^{2}$ Exceçôes são os livros de Grondin (1985); de Andrade (2019) e, é claro, a tradução muito tardia de James (2000), editada pela primeira vez em 1938.
}

revolucionária no Caribe. A perspectiva não é exatamente comparativa, mas leva em conta a diversidade de experiências coloniais e a grande expansão econômica baseada no boom da produção de açúcar na região. Aqui são consideradas também as formas de dominação oriundas de diferentes autoridades europeias a partir da vitória contra os piratas, bucaneiros e renegados que ocupavam aquelas ilhas e se organizavam por meio de regras próprias. Foi ao longo do século XVIII que a presença de escravizados africanos passou a se dar no Caribe de forma massiva - o que, se veio a transformar substantivamente a região, ao mesmo tempo manteve a imagem daquelas ilhas como lugares atrativos para desertores, escravos fugidos e toda a multidão de gente espoliada que pretendia viver sem obedecer às ordens de senhores.

$\mathrm{O}$ capítulo 2, "Negroes in Foreign Bottoms': Sailors, Slaves, and Communication”, remete à visão de mundo de escravizados e seus senhores. Ambos reconheciam o potencial transformador do conhecimento das técnicas e formas de navegação. Tratava-se de algo perigoso e que criava homens insolentes, na visão senhorial, e que tendia para a construção de uma igualdade, no entendimento dos escravos. Olaudah Equiano, escravo marinheiro em meados do século XVIII e autor de uma celebrada autobiografia que parece guiar o capítulo, percebeu claramente que a mobilidade advinda dessa ocupação permitia certa igualdade com seus senhores, e não hesitou em "dizê-lo para sua mente". Desgraçadamente para os senhores, muitos escravos com dificuldades de aceitar a disciplina que 
se lhes queria impor se engajaram no mundo do trabalho marítimo, inclusive porque seus senhores queriam se ver livres deles justamente por serem indisciplinados.

O terceiro capítulo, "The Suspense Is Dangerous in a Thousand Shapes': News, Rumor, and Politics on the Eve of the Haitian Revolution", pretende dar um aporte maior ao entendimento da revolucionária década de 1790 considerando seus antecedentes. $\mathrm{O}$ foco está dirigido à mobilidade de escravos, homens livres de cor e desertores militares e da marinha mercante que circulavam entre uma propriedade e outra, entre o campo e as cidades e entre as diversas ilhas, colocando em questão o controle social e a autoridade imperial. Ao fazer isso, alimentaram uma tradição de "resistência móvel" construída ao longo do Setecentos e que se radicalizaria nas décadas finais daquele século e no início do Oitocentos. As reaçóes e tentativas de controle social mais severo por parte de autoridades metropolitanas e coloniais inglesas, espanholas e francesas são apresentadas nesse capítulo.

O capítulo 4, "Ideas of Liberty Have Sunk So Deep': Communication and Revolution, 1789-93", lança novas luzes sobre a repercussão da Revolução no Haiti nas demais ilhas. Ideias revolucionárias circularam não apenas em busca de adeptos, mas também como estratégia das autoridades imperiais em interação repressiva. Além de informações, oficiais baseados em uma ilha trocavam, com seus homólogos de outras Coroas, ajuda de todo tipo, militar inclusive. Os da Martinica pediram tropas ao governador de Cuba em 1790, diante das desordens que enfrentavam naquela colônia e da confusão revolucionária em que a própria metrópole francesa mergulhara em 1789, inviabilizando o envio de qualquer apoio. A causa da manutenção do controle social ultrapassava fronteiras linguísticas, imperiais e senhoriais. Mas os acontecimentos de 1789 e 1790 no Caribe, como afirma Scott, também ativaram as redes de comunicação afro-americanas. Se autoridades e proprietários ingleses, espanhóis e franceses construíram diálogos e articularam açóes para se autopreservarem no Caribe ao longo do tempo, os escravos e homens livres de cor fizeram o mesmo.

O quinto capítulo, "Knows Your Interests': Saint-Domingue and the Americas, 1793-1800", concentra-se no impacto pós-revolucionário nos impérios coloniais remanescentes e nos Estados Unidos. Porém, a amplitude geográfica do capítulo é menor do que o título promete. Houve mobilização militar nas colônias, num esforço para manter a ordem. Os escravos, por sua vez, mobilizaram-se e articularam ações que não foram apenas respostas ao aumento da severidade e da vigilância, mas que diziam respeito às suas próprias tradições organizativas. Esse processo foi intenso em $\mathrm{Cuba}^{3}$, na porção oriental de Hispaniola, na Venezuela, em Curaçao e na Luisiana, apenas para mencionar algumas colônias em que a escravidão era a base da exploração dos trabalhadores. Desafortunadamente, a América portuguesa, maior colônia escravista do continente, ficou fora do quadro comparativo, decerto

\footnotetext{
${ }^{3} \mathrm{O}$ impacto da Revolução do Haiti em Cuba pode ser conhecido pelo leitor brasileiro com mais detalhes pelos trabalhos já traduzidos de Ada Ferrer (2010 e 2012).
} 
pela falta de domínio da língua portuguesa por parte do autor e pela reduzida bibliografia sobre a repercussão da Revolução Haitiana produzida no Brasil e em Portugal.

A circulação ou mobilidade espacial é o grande tema do livro. Negros africanos ou nascidos no Caribe e mestiços iam de uma colônia às outras, navegando distâncias que, embora relativamente curtas, lhes davam acesso a comunidades estrangeiras, com diferentes línguas e experiências de escravização e resistência. As oportunidades de disseminar conhecimentos e ideias e trocar informaçóes objetivas não foram perdidas por aqueles escravos que se ganharam o mar e o mundo além do horizonte. $\mathrm{O}$ movimento dos navios e dos marinheiros oferecia não só oportunidades de desenvolver habilidades ou viabilizar fugas, mas criava formas de comunicação de longa distância e permitia que os afro-americanos transportassem, física e simbolicamente, seus modos de enfrentar as adversidades do cativeiro a outras partes, construindo resistências e concepçóes de liberdade globais.

A cultura marítima no Caribe era multirracial e multinacional. Escravos africanos ou nascidos nas colônias americanas eram partes importantes do contingente de trabalhadores do mar, mas o "submundo dos marinheiros" na regiāo ao fim do século XVIII era formado também por milhares de britânicos e franceses. Tratava-se de uma populaçáo instável e que, por vezes, em razão de questóes de mercado de trabalho ou de saúde, se estabelecia em alguma ilha à espera de melhores condiçóes, enraizando-se na cultura local de transitoriedade e de exposição às informaçôes que circulavam ra- pidamente para os padróes daqueles tempos. No Caribe sabia-se dos acontecimentos das ilhas vizinhas, da Europa e da América do Norte: ali era a encruzilhada do mundo Ocidental, mais especificamente do hemisfério Norte, graças às correntes de comunicaçáo estimuladas pela relativa proximidade, pelas facilidades da navegaçáo e pelo aumento da atividade agroexportadora caribenha ao longo do século XVIII.

$\mathrm{O}$ axioma segundo o qual marinheiros eram desordeiros em terra encontrava plena comprovação no Caribe. Milhares de homens em trânsito representavam um problema para as autoridades locais responsáveis pela manutenção da ordem. Inúmeras leis foram postas em vigor para discipliná-los, do mesmo modo como se fazia para tentar regular a conduta dos escravos. Em tempos mais explicitamente conflituosos, como na Guerra dos Dez Anos (1780-1790), chegou-se a proibir que marujos britânicos nas Índias Ocidentais servissem a príncipes ou Estados estrangeiros. A proibição mostrou-se ineficaz.

A comparação entre escravos e marinheiros não é aleatória no trabalho de Scott. Ele nos deixa ver como ambos tiveram experiências em comum e causas pelas quais militavam juntos: o engajamento compulsório independentemente da condição, a submissão a punições arbitrárias, a pressão para embarcarem em navios mercantes contra sua vontade e a visáo sobre ambos como perturbadores da ordem pública. Bom exemplo foi um ato policial de 1789, em Granada, prevendo penalizar escravos, mestiços livres e marinheiros que atentassem contra a própria saúde e a moral, porque seus comportamen- 
tos, vistos como dissolutos, eventualmente seduziam pessoas de outras condiçóes.

Escravos e marinheiros conviviam a bordo, como tripulantes dos mesmos navios, mas a experiência também replicava em terra. Marinheiros eram os consumidores naturais das roças escravas caribenhas e, apesar do empenho policial, era difícil impedir que escravos lavradores ou em fuga fizessem comércio com marinheiros famintos e fragilizados depois de uma longa viagem, ávidos sobretudo por frutas e outros alimentos frescos. O contato e o convívio entre marinheiros e negros naquelas ilhas não tiveram apenas consequências econômicas, mas também forjaram elementos da cultura: muitas canções de trabalho populares no mar, disseminadas por marujos britânicos pelo mundo afora no século XIX, têm extraordinária semelhança com as cançóes escravas do Caribe. Scott afirma haver evidências consideráveis de que muitas cançóes podem ter se originado da interação de marinheiros e negros nas docas das Índias Ocidentais e que a teoria da origem e desenvolvimento das línguas crioulas no Caribe enfatiza o contato entre marinheiros europeus e escravos africanos e africano-americanos.

O ponto de intersecção de toda essa gente trabalhando em trânsito era Saint-Domingue, lugar de extraordinária diversidade de grupos de marinheiros europeus, a julgar pelos relatos do próprio ministério da Marinha francês na década de 1790. Mesmo com os monopólios coloniais e suas diferentes nomenclaturas (a flota espanhola, o exclusif francês, o British Navigation Act inglês), o contrabando grassava por ali, pondo em contato colonos europeus, marinheiros de diferentes metrópoles e escravos caribenhos e de variadas origens africanas. A razão dessa diversidade também entre os escravos, para além do tráfico direto com a África, era a sede por mão de obra em Saint-Domingue, o que fazia daquela colônia francesa um repositório de escravos fugidos a partir de 1770, vindos de Jamaica, Curaçao e, a julgar pela língua de alguns deles, também do Brasil. Muitos desses escravos em fuga se engajaram ativamente em rebeliōes antes mesmo de 1789 e desempenharam papéis relevantes nos anos revolucionários - por exemplo Henry Christophe, segundo presidente do Haiti independente, nascido em St. Kitts, nas Índias Ocidentais britânicas.

O comércio e a circulação de marinheiros por aquelas bandas não só traziam notícias de fora como transmitiam ao resto do mundo o que se passava em Saint-Domingue. Scott reconhece que as revoltas de negros no Caribe em fins do século XVIII inspiraram os escravos nos Estados Unidos e em muitas das Antilhas. Em termos materiais, a afirmação encontra base no volume comercial entre Estados Unidos e Saint-Domingue em 1790: o montante das trocas, nessa altura, excedia aquelas feitas com todo o restante do continente americano, e era superado apenas pelo comércio com a Grã-Bretanha.

Scott foi um dos primeiros historiadores a identificar na mobilidade espacial advinda da navegação um importante indicador de autonomia e, eventualmente, liberdade para os cativos que conseguissem trilhar esse caminho. Os navios carregados de açúcar e rum circulando pelo Caribe possibilitavam esca- 
par do rigoroso controle social existente nas sociedades escravistas e principalmente os navios menores eram vistos como instrumentos de fuga. Problemas diplomáticos e policiais decorriam dessa mobilidade não autorizada, mas o foco do autor se firma nos marinheiros e escravos desertores que elegeram as ilhas caribenhas como seus locais preferidos.

No Atlântico, mais do que em outros oceanos, e no Caribe, de forma concentrada, o comércio marítimo de longa distância e de cabotagem envolvia homens escravos e livres de cor. No caso dos escravos, envolvia também perspectivas de autonomia e liberdade dadas não só pela mobilidade como também pelas chances de se diluir em meio à multidão reunida nos portos, formada por indivíduos que, ao serem observados, não podiam ser definidos como livres ou cativos apenas pela cor de suas peles. Os mesmos jornais jamaicanos que publicavam anúncios de senhores vendendo negros especializados em trabalhos marítimos também publicavam anúncios de fuga de gente que certamente usara o mar como rota para desaparecer das vistas de seus senhores. Scott interpreta a "mística do mar" nas sociedades escravistas insulares do Caribe, ao salientar a vida a bordo de um pequeno navio de cabotagem ou do comércio intercolonial como uma alternativa atrativa à vida marcada pela hierarquia severa nas lavouras açucareiras. Mesmo escravos sem experiência marítima podiam conhecer alguns termos náuticos graças aos versos das cançóes populares e fingirem serem marinheiros livres. Ávidos por força de trabalho, os capitães dos navios quase nunca inquiriam cuidadosamente cada marinheiro engajado.
Durante a década de 1790, antes e depois da Revolução de Saint-Domingue, sujeitos envolvidos no mundo do trabalho marítimo - marinheiros da navegação de longa distância, de pequenos navios de cabotagem no comércio intercolonial, escravos fugidos, marujos desertores brancos e negros - assumiram o centro do palco. No mar ou em terra, homens e mulheres sem senhores desempenharam um papel vital, espalhando rumores, reportando notícias e atuando como correia de transmissão de movimentos antiescravistas e, finalmente, da revolução republicana em curso na Europa.

A Revolução do Haiti tornou-se lendária não só porque foi a primeira experiência de liberdade coletiva e de construção de uma nação por ex-escravizados que retiraram à força seus senhores de cena, mas também pelo que representou como possibilidade na imaginação de escravos e senhores espalhados pelo mundo ocidental onde a escravidão era a base da acumulação de riquezas. A crença na determinação histórica, fruto da autocondescendência pela suposta descoberta de modelos explicativos eficazes, encontra nesta encruzilhada do Ocidente um incômodo para os historiadores mais seguros de suas opçóes teóricas. $\mathrm{O}$ passado torna-se sempre mais complexo quando é considerado da perspectiva de seus agentes.

\section{Referências}

ANDRADE, Everaldo de Oliveira. Haiti, dois séculos de história. São Paulo: Alameda, 2019. 
FERRER, Ada. A sociedade escravista cubana e a Revolução Haitiana. Almanack, n. 3, p. 37-53, jun. 2012.

FERRER, Ada. A sociedade escravista cubana na época da Revoluçáo Haitiana. In: CUNHA, Olívia Maria Gomes da. Outras ilhas: espaços, temporalidades e transformaçóes em Cuba. Rio de Janeiro: Aeropolano/FAPERJ, 2010. p. 37-64.

GRONDIN, Marcelo. Haiti. Col. Tudo é História. São Paulo: Brasiliense, 1985.

JAMES, Cyril Lionel Robert [1938]. Os jacobinos negros: Toussaint L'Ouverture e a revolução de São Domingos. São Paulo:

Boitempo, 2000.
REDIKER, Marcus. O navio negreiro: uma história humana. São Paulo: Companhia das Letras, 2011.

REDIKER, Marcus; LINEBAUGH, Peter. A bidra de muitas cabeças: marinheiros, plebeus e a história oculta do Atlântico revolucionário. Sáo Paulo: Companhia das Letras, 2008.

SCOTT, Julius S. The Common Wind: AfroAmerican Currents in the Age of the Haitian Revolution. Londres; Nova York: Verso, 2018. 